\title{
The influence of growth medium on serum sensitivity of Bacteroides species
}

\author{
E. ALLAN and I. R. POXTON* \\ Department of Medical Microbiology, University of Edinburgh Medical School, Teviot Place, Edinburgh EH8 9AG
}

\begin{abstract}
Summary. The susceptibility of 12 different Bacteroides strains (representing nine species) to the bactericidal effect of human serum complement was investigated. When grown in nutrient-rich proteose peptone-yeast extract medium, all 12 strains were, to varying degrees, sensitive to serum. However, when grown in Van Tassell and Wilkins's minimal medium, six of the 12 strains became markedly more serum resistant. Five of these six strains became totally resistant to serum when grown in heat-inactivated $\left(56^{\circ} \mathrm{C}, 30 \mathrm{~min}\right)$ sheep serum. By Percoll discontinuous density centrifugation and light microscopy, the ratio of bacteria with large and small capsules was found to vary with the growth medium used. Lipopolysaccharide (LPS) was extracted with aqueous phenol after growth in the three media. Polyacrylamide gel electrophoresis (PAGE) and silver staining of the LPS showed some differences in LPS profiles in all strains tested. Therefore, variation of growth conditions results in alterations of both the expression of surface structures and, in some cases, sensitivity to serum. The biochemical basis for these changes requires further investigation.
\end{abstract}

\section{Introduction}

Members of the genus Bacteroides (formerly the Bacteroides fragilis group) are common components of the healthy colonic flora and are often involved in both pure and mixed infections in man-e.g., intraabdominal abscesses, bacteraemia, wound and urogenital infections. B. fragilis, the type species, is the anaerobe isolated most commonly from clinical specimens, and the most common cause of anaerobic bacteraemia. ${ }^{1-4}$ The surface polysaccharides of the $B$. fragilis group are widely considered to be major virulence determinants. ${ }^{5,6}$ However, despite extensive research, there is still debate as to whether the lipopolysaccharide (LPS) of $B$. fragilis is rough $^{5}$ or smooth $^{7}$ and the roles of the capsule and LPS as virulence factors are unclear. This is further confused by the recognition, which has not been considered by many workers, that following fractionation by Percoll discontinuous density centrifugation, ${ }^{8}$ a wild-type laboratory culture of $B$. fragilis has been shown to be morphologically heterogeneous with respect to both size $^{9}$ and antigenicity ${ }^{10,11}$ of its capsule.

Resistance to the bactericidal effects of serum complement has been clearly shown to be associated with virulence in a wide range of species. ${ }^{12,13}$ In some cases, the mechanism of resistance is known, and both the $O$ polysaccharide of LPS and capsular polysaccharide (CP) have been implicated as important virulence determinants. For example, wild-type Sal-

Received 9 Dec. 1993; accepted 19 Jan. 1994.

* Correspondence should be sent to Dr I. R. Poxton. monella minnesota (with smooth LPS) is highly resistant to complement, whereas the rough mutant is extremely sensitive.$^{14}$ In the case of Escherichia coli $\mathrm{K} 1$ strains, the CP is responsible for complement resistance. ${ }^{15}$

Previous studies have shown that Bacteroides strains isolated from infections are generally more resistant to complement than those isolated from faeces. ${ }^{16}$ Clinical isolates of $B$. fragilis have been found to be more resistant to complement than clinical isolates of other Bacteroides species. $^{17}$ Also, complement-resistant strains of $B$. fragilis have been shown to survive better than complement-sensitive strains in a subcutaneous model of infection. ${ }^{18}$ However, the mechanism of complement resistance in Bacteroides strains is un-

Table I. Bacteroides strains

\begin{tabular}{lll}
\hline Species & Strain no. & Source \\
\hline B. fragilis & MPRL 1504 & Wound \\
B. fragilis & NCTC 9343 & Appendix abscess \\
B. uniformis & ATCC 8492 & Unknown \\
B. vulgatus & MPRL 1985 & Faeces \\
B. vulgatus & MPRL 1651 & Faeces \\
B. caccae & MPRL 1555 & Wound \\
B. ovatus & MPRL 2370 & Blood \\
B. eggerthii & NCTC 11155 & Faeces \\
B. distasonis & ATCC 8503 & Unknown \\
B. thetaiotaomicron & MPRL 1959 & Blood \\
B. thetaiotaomicron & NCTC 10582 & Faeces \\
B. variabilis & VPI 11368 & Unknown \\
\end{tabular}

MPRL, departmental stock culture; NCTC, National Collection of Type Cultures; ATCC, American Type Culture Collection; VPI. Virginia Polytechnic Institute, USA. 
known, but CP is not thought to enhance resistance, ${ }^{19}$ while the role of LPS is unclear.

It is well recognised that the growth environment of bacteria greatly influences the phenotypic expression of surface molecules. This can be fundamental in the adaptive process that enables an invading pathogenic bacterium to survive. ${ }^{20,21}$ The aims of this study were: to investigate whether different growth conditions affected the sensitivity of Bacteroides spp. to serum; to determine whether any change in sensitivity was concomitant with a change in surface chemistry; and to investigate whether different methods of processing serum affected its bactericidal capabilities.

\section{Materials and methods}

\section{Bacteria and growth conditions}

The strains used and their source are listed in table I. Bacteria were grown to early stationary phase in nutrient-rich proteose peptone-yeast extract medium (PPY), ${ }^{22}$ Van Tassell and Wilkins's minimal medium (VT and $\mathrm{W})^{23}$ and heat-inactivated $\left(56^{\circ} \mathrm{C}, 30 \mathrm{~min}\right)$ sheep serum (HISS). Cultures were incubated at $37^{\circ} \mathrm{C}$ in an atmosphere of $\mathrm{H}_{2} 10 \%, \mathrm{CO}_{2} 10 \%$ and $\mathrm{N}_{2} 80 \%$ in an anaerobic cabinet (Forma), and were checked for purity by Gram's stain and by aerobic and anaerobic incubation on Columbia Blood Agar (Oxoid).

\section{Collection of serum}

Human serum, used as a source of complement, was collected from five healthy adult volunteers in two ways as follows. (A) Freshly drawn blood was allowed to clot at $37^{\circ} \mathrm{C}$ for $30 \mathrm{~min}$, then centrifuged at $4000 \mathrm{~g}$ for $10 \mathrm{~min}$. Sera were removed, centrifuged as before and the supernates were pooled and stored at $-70^{\circ} \mathrm{C}$ in 1-ml volumes until just before use. (B) Freshly drawn blood was left to clot overnight at room temperature. It was then placed at $4^{\circ} \mathrm{C}$ for $30 \mathrm{~min}$ before removal of serum. The sera were centrifuged at $4000 \mathrm{~g}$ for $10 \mathrm{~min}$ before the supernates were pooled and stored at $-70^{\circ} \mathrm{C}$ in $1-\mathrm{ml}$ volumes until just before use.

The haemolytic complement value ( $\mathrm{CH} 50)$ of the individual and pooled serum samples was checked as described previously ${ }^{24}$ except that phosphate-buffered saline (PBS; Oxoid) was used instead of barbitonebuffered saline. Frozen specimens were thawed only once.

\section{Serum sensitivity assay}

Bacteria washed once in complement fixation test buffer (CFTB; Oxoid) were resuspended to a concentration of c. $10^{5} \mathrm{cfu} / \mathrm{ml}$ in either CFTB only (control), CFTB + serum $10 \%$ or CFTB + serum $40 \%$ and incubated aerobically ( $2 \mathrm{ml}$ in $2 \cdot 5$ - $\mathrm{ml}$ closed plastic tubes) at $37^{\circ} \mathrm{C}$ for $2 \mathrm{~h}$ with end-over-end rotation. Samples $(100 \mu \mathrm{l})$ were taken at 0,1 and $2 \mathrm{~h}$, diluted 1 in 50 in CFTB, and $100 \mu$ lof the resulting suspension were spread on Columbia blood agar in duplicate.
After anaerobic incubation for $48 \mathrm{~h}$, colonies were counted and the percentage survival compared to the control was calculated. All experiments were repeated at least twice. As a further control, all bacteria found to be sensitive to serum were resuspended to $10^{5} \mathrm{cfu} /$ $\mathrm{ml}$ in $\mathrm{CFTB}$ + heat-inactivated $\left(56^{\circ} \mathrm{C}, 30 \mathrm{~min}\right)$ human serum $40 \%$ and treated as above. In a preliminary experiment complement-mediated killing in an anaerobic environment with reduced (anaerobic) buffers was compared with the aerobic system described above. No differences were seen in bacterial survival.

\section{Percoll gradients}

Cell capsulation was assessed by Percoll (Pharmacia) discontinuous density centrifugation. Percoll was diluted as described previously, ${ }^{8}$ and a step gradient was produced by layering $1-\mathrm{ml}$ volumes of $80 \%$ (bottom), then $60 \%, 40 \%$ and $20 \%$ (top) Percoll into $70 \times 20$-mm glass test tubes. A sample of an early stationary phase culture of the test organism $(1.25 \mathrm{ml})$ was applied to the top of the $20 \%$ layer and the gradient was centrifuged at $2600 \mathrm{~g}$ for $20 \mathrm{~min}$.

\section{LPS preparation}

LPS was prepared from washed cells obtained from a $10-\mathrm{ml}$ early stationary phase culture by the micromethod developed by Fomsgaard et al. ${ }^{25}$ which was based on the aqueous phenol method of Westphal and Luderitz. $^{26}$

\section{PAGE}

PAGE was performed on acrylamide $14 \% \mathrm{w} / \mathrm{v}$ slab gels with the Laemmli buffer system, ${ }^{27}$ except that SDS was omitted from the stacking and separating buffers. Samples $(20 \mu 1)$ of the aqueous phenol LPS extracts were loaded on the gels and the separating gel was stained with silver by the method developed by Tsai and Frasch, ${ }^{28}$ as modified by Hancock and Poxton. ${ }^{29}$

\section{Results}

\section{Comparison of two methods of serum processing}

Human serum processed by methods $\mathrm{A}$ and $\mathrm{B}$ was tested for its ability to kill $B$. fragilis MPRL 1504, $B$. fragilis NCTC 9343 and B. vulgatus MPRL 1985 grown in PPY (table II). With all three strains, serum processed by method A was more bactericidal than that processed by method $\mathrm{B}$. The $\mathrm{CH} 50$ values of the sera (method $A=63.1$ units $/ \mathrm{ml}$, method $B=$ $49 \cdot 1$ units $/ \mathrm{ml}$ ) showed complement activity to be better preserved in serum processed by method A. Therefore, in all subsequent experiments, serum processed by method A was used.

\section{Serum sensitivity of 12 Bacteroides strains grown in three different media}

The 12 Bacteroides strains listed in table I were grown in three different media (PPY, VT and W, and 
Table II. Complement killing of three Bacteroides strains grown in PPY by serum processed by two different methods

\begin{tabular}{|c|c|c|c|}
\hline \multirow{2}{*}{ Strain } & \multirow{2}{*}{$\begin{array}{l}\text { Assay } \\
\text { medium }\end{array}$} & \multicolumn{2}{|c|}{$\begin{array}{l}\text { Percentage of cells } \\
\text { surviving* with }\end{array}$} \\
\hline & & $\begin{array}{c}\text { Method A } \\
(\mathrm{CH} 50=63 \cdot 1)\end{array}$ & $\begin{array}{c}\text { Method B } \\
(\mathrm{CH} 50=49 \cdot 1)\end{array}$ \\
\hline \multirow[t]{2}{*}{$\begin{array}{l}\text { B. fragilis } \\
\text { MPRL } 1504\end{array}$} & $\begin{array}{l}\text { CFTB only } \\
\text { (control) }\end{array}$ & 95.2 & 94.6 \\
\hline & $\begin{array}{l}10 \% \text { serum } \\
40 \% \text { serum }\end{array}$ & $\begin{array}{l}8.9 \\
7.8\end{array}$ & $\begin{array}{l}16 \cdot 1 \\
10 \cdot 1\end{array}$ \\
\hline \multirow{2}{*}{$\begin{array}{l}\text { B. fragilis } \\
\text { NCTC } 9343\end{array}$} & CFTB only & $95 \cdot 3$ & 93.8 \\
\hline & $\begin{array}{l}10 \% \text { serum } \\
40 \% \text { serum }\end{array}$ & $\begin{array}{l}55 \cdot 1 \\
14 \cdot 2\end{array}$ & $\begin{array}{l}77 \cdot 6 \\
37 \cdot 3\end{array}$ \\
\hline \multirow[t]{2}{*}{$\begin{array}{l}\text { B. vulgatus } \\
\text { MPRL } 1985\end{array}$} & $\begin{array}{l}\text { CFTB only } \\
\text { (control) }\end{array}$ & 91.9 & 93.0 \\
\hline & $10 \%$ serum & $\begin{array}{l}56 \cdot 2 \\
49 \cdot 8\end{array}$ & $\begin{array}{l}68 \cdot 3 \\
58 \cdot 3\end{array}$ \\
\hline
\end{tabular}

*Survival after $1 \mathrm{~h}$ compared to time 0 .

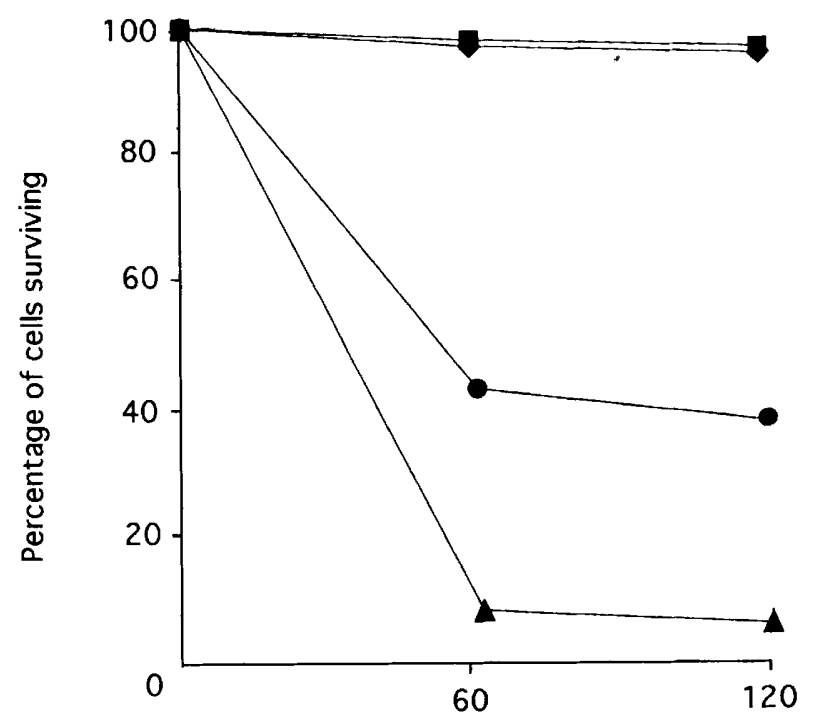

Time of exposure to serum ( $\mathrm{min})$

Fig. 1. Survival of $B$. fragilis MPRL 1504 in $40 \%$ human serum after growth in three media: $-\mathbf{-}$ control (no serum); $\mathbf{\Delta}-\mathbf{\Delta}$ PPY; VT and W; - HISS. Points shown are mean percentage survival calculated from four replicates.

HISS) and then tested for their ability to survive in $10 \%$ human serum, $40 \%$ human serum and buffer only (control). Table III shows the results for all 12 strains with $40 \%$ serum. When grown in PPY, all strains were sensitive to serum to varying degrees. However, when grown in VT and W, six of the 12 strains (B. fragilis MPRL 1504, B. fragilis NCTC 9343, $B$. caccae MPRL 1555, B. thetaiotaomicron MPRL 1959, B. ovatus MPRL 2370 and B. vulgatus MPRL 1985 ) became markedly more resistant to serum. With the exception of B. vulgatus MPRL 1985, these strains became totally resistant to serum when grown in HISS. In every case, survival in CFTB alone was between 90 and $100 \%$. Fig. 1 shows the survival of $B$. fragilis MPRL 1504 in serum after growth in the three
Table III. Survival of 12 Bacteroides strains after $1 \mathrm{~h}$ in $40 \%$ human serum following growth in three media

\begin{tabular}{|c|c|c|c|}
\hline \multirow{2}{*}{ Strain no. } & \multicolumn{3}{|c|}{$\begin{array}{c}\text { Percentage survival of } \\
\text { bacteria grown in }\end{array}$} \\
\hline & PPY & VT and W & HISS \\
\hline B. fragilis MPRL 1504 & $7 \cdot 8$ & $37 \cdot 9$ & $92 \cdot 2$ \\
\hline B. fragilis NCTC 9343 & $14 \cdot 2$ & $68 \cdot 1$ & $94 \cdot 2$ \\
\hline B. caccae MPRL 1555 & $10 \cdot 2$ & $48 \cdot 9$ & $91 \cdot 3$ \\
\hline B. ovatus MPRL 2370 & $74 \cdot 4$ & $85 \cdot 6$ & $98 \cdot 1$ \\
\hline B. thetaiotaomicron MPRL 1959 & $52 \cdot 9$ & $71 \cdot 8$ & $97 \cdot 6$ \\
\hline B. thetaiotaomicron NCTC 10582 & $23 \cdot 3$ & $19 \cdot 7$ & $25 \cdot 1$ \\
\hline B. uniformis ATCC 8492 & $13 \cdot 0$ & $11 \cdot 3$ & $10 \cdot 6$ \\
\hline B. vulgatus MPRL 1985 & $49 \cdot 8$ & $61 \cdot 1$ & $41 \cdot 5$ \\
\hline B. vulgatus MPRL 1651 & $14 \cdot 4$ & $21 \cdot 5$ & $15 \cdot 5$ \\
\hline B. eggerthii NCTC 11155 & $0 \cdot 0$ & $3 \cdot 2$ & $0 \cdot 0$ \\
\hline B. distasonis ATCC 8503 & $6 \cdot 7$ & $0 \cdot 0$ & $2 \cdot 6$ \\
\hline B. variabilis VPI 11368 & $0 \cdot 0$ & $0 \cdot 0$ & $1 \cdot 2$ \\
\hline
\end{tabular}

media. Heat inactivation of serum destroyed bactericidal activity in every case where a strain was killed by active serum.

\section{Capsulation of cells in three media}

A step gradient of Percoll was used to assess the degree of capsulation of the 12 Bacteroides strains grown in three different media. All of the strains (except B. eggerthii NCTC 11155 which was noncapsulate) had a characteristic ratio of cells with large:small:no capsule, and in all cases, this ratio varied with the growth medium. The Percoll gradients of $B$. fragilis MPRL 1504 after growth in the different media are shown in fig. 2a. India ink smears of the three cell types of B. fragilis MPRL 1504 (i.e., large, small, no capsule), extracted from the Percoll gradients, are shown in fig. 2 b. 

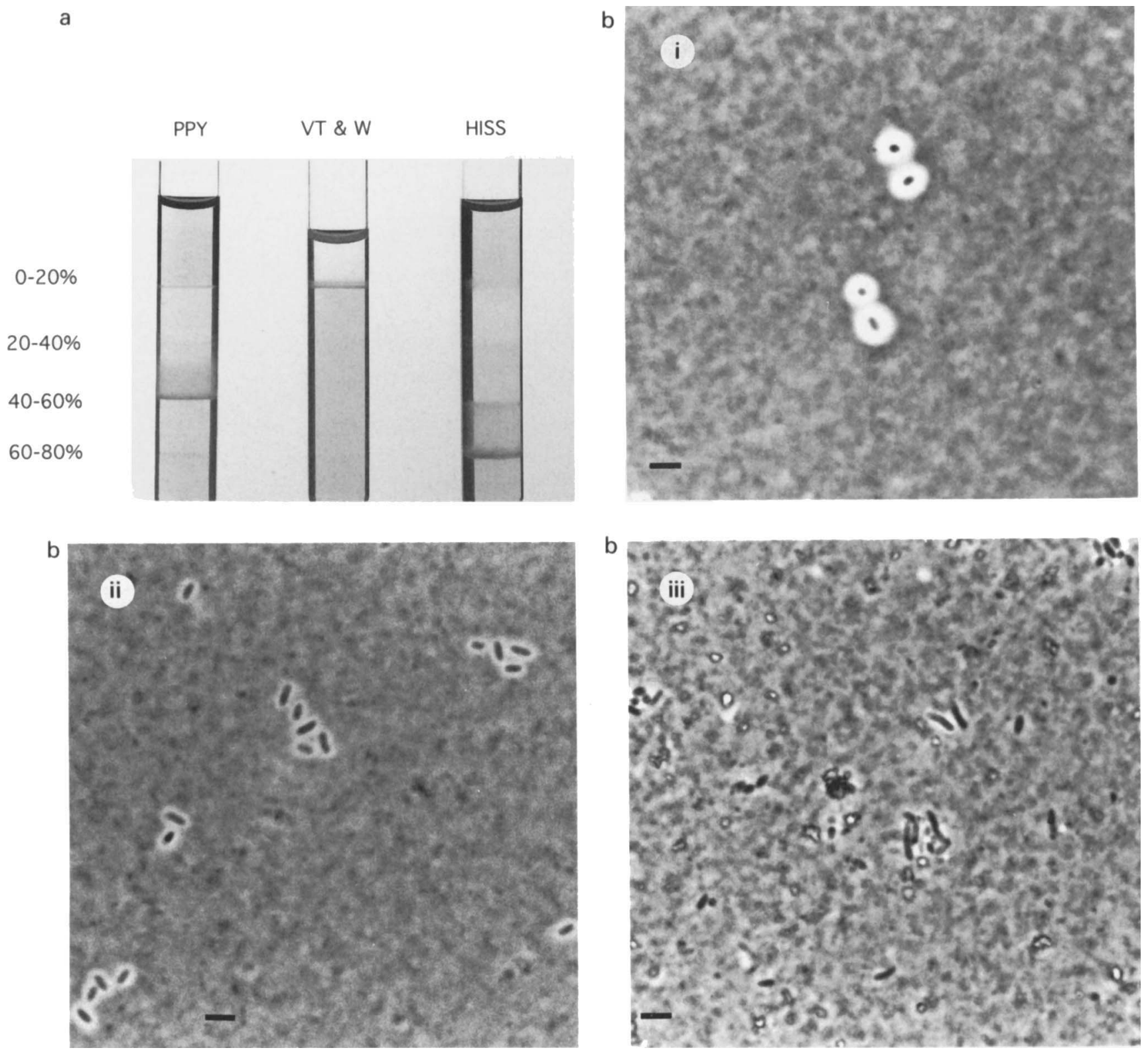

Fig. 2. a, four-step $(20,40,60$ and $80 \%)$ Percoll density gradients after centrifugation with cultures of $B$. fragilis MPRL 1504 grown in three media. Cells with large capsules were found at the $0-20 \%$ interface, those with small capsules at the $20-40 \%$ and $40-60 \%$ interfaces and those with no capsule at the $60-80 \%$ interface. b, photomicrographs of B. fragilis MPRL 1504 showing bacteria with: $\mathbf{i}$, large capsules (from VT and W); ii, small capsules (from PPY); iii, no capsules (from HISS). Cells were removed from the most concentrated band in each of the Percoll gradients and stained with India ink. Bar markers $=c .2 \mu \mathrm{m}$.

\section{LPS profiles of bacteria grown in three media}

The LPS profiles of all 12 Bacteroides strains grown in the three media were examined by aqueous phenol extraction followed by PAGE and silver staining. Fig. 3 shows the silver-stained PAGE profiles of the LPS of the six strains that showed most altered sensitivity to serum in different media. Each species had a characteristic profile, with some obvious differences seen in that of any given strain when grown in different media. B. vulgatus was the only species to show a distinct ladder pattern that is characteristic of smooth LPS as seen in enterobacteria, and this strain showed the least differences in staining pattern. Other profiles were similar to those published previously, ${ }^{7,30}$ with low $M_{r}$ bands characteristic of rough or semi-rough strains, but all also had a few strongly staining high $M_{r}$ bands which we have shown previously to be made up of closely spaced ladder patterns. ${ }^{7}$ The apparent weak staining of $B$. fragilis MPRL 1504 (tracks 4-6) is probably because this is an extremely mucoid strain and much of the extract may be of such a high $\mathrm{M}_{\mathrm{r}}$ that it is unable to enter the polyacrylamide gel. There is no obvious correlation between pattern and change in sensitivity to serum.

\section{Discussion}

The mode of action of the complement system is now largely understood, and some bacterial resistance mechanisms to its lethal effects are known. However, a major drawback in experimental work on this system 


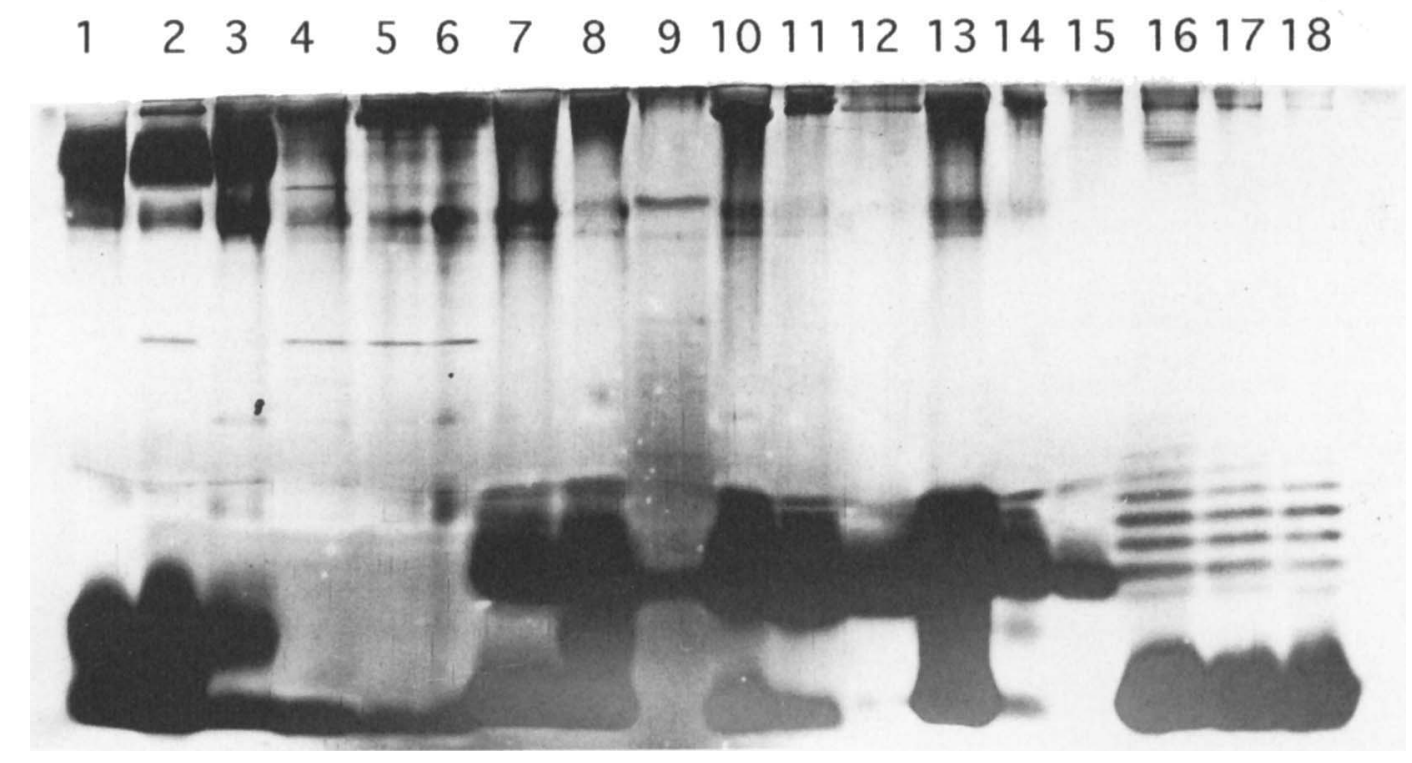

Fig. 3. Silver-stained PAGE (14\% acrylamide) LPS profiles of aqueous phenol extracts of six Bacteroides strains following growth to early stationary phase in PPY, HISS and VT and W. Tracks: 1, B. fragilis NCTC 9343 (PPY); 2, B. fragilis NCTC 9343 (VT and W); 3, B. frayilis NCTC 9343 (HISS); 4, B. fragilis MPRL 1504 (PPY); 5, B. fragilis MPRL 1504 (VT and W); 6, B. fragilis MPRL 1504 (HISS); 7, B. caccae MPRL 1555 (PPY); 8, B. caccae MPRL 1555 (VT and W); 9, B. caccae MPRL 1555 (HISS); 10, B. ovatus MPRL 2370 (PPY); 11, B. otatus MPRL 2370 (VT and W); 12, B. ovatus MPRL 2370 (HISS); 13, B. thetaiotaomicron MPRL 1959 (PPY); 14, B. thetaiotaomicron MPRL 1959 (VT and W); 15, B. thetaiotaomicron MPRL 1959 (HISS); 16, B. vulgatus MPRL 1985 (PPY); 17, B. vulgatus MPRL 1985 (VT and W); 18, B. vulgatus MPRL 1985 (HISS).

is that there is no standardised method for testing serum sensitivity, and also no universal definition of serum sensitivity. ${ }^{13}$ Many papers do not specify how serum used in sensitivity experiments was processed and stored. This study has shown that different methods of processing serum affect complement activity (and therefore bacterial killing), and so may significantly affect the outcome of an experiment and the conclusions drawn from it.

Previous studies investigating the susceptibility of Bacteroides spp. to serum have done so after growth in one medium only. However, this study has shown dramatic changes in the sensitivity of some Bacteroides strains to serum when growth medium is altered. These results demonstrate a need to take growth medium into consideration when assessing serum sensitivity of bacteria, and also possibly when assessing other virulence factors.

All the Bacteroides strains in this study that became totally resistant to serum when grown in HISS (table II) were of clinical origin (table I). This is in agreement with a previous study by Casciato et al., ${ }^{16}$ who found that faecal isolates of Bacteroides were significantly more sensitive to serum than those isolated from clinical infections. Resistance to complementmediated killing is a well recognised virulence factor and is usually associated with the presence of a capsule or smooth LPS. This relationship does not seem to hold for the Bacteroides strains investigated here. $B$. fragilis MPRL 1504 grown in HISS was non-capsulate, and was resistant to complement, whereas the cap- sulate cells (grown in PPY and VT and W) were sensitive. This is in agreement with a previous study, where Reid and Patrick ${ }^{19}$ found the non-capsulate variant of $B$. fragilis ATCC 23745 to be resistant to complement, and the capsulate variant to be sensitive. Of the other four strains in this study that became resistant to serum after growth in HISS, two were mainly non-capsulate and two were capsulate. Although differences were seen in the LPS patterns of any given strain when grown in three different media, we were unable to relate changes in pattern to changes in sensitivity to serum. However, the resolution of Bacteroides LPS with silver staining tends to be much poorer than that of many other organisms (e.g., the Enterobacteriaceae). ${ }^{21,31}$ Also, we suspect that certain high $\mathbf{M}_{r}$ polysaccharides may not be entering the gel and it is, therefore, possible that there were differences that were undetected by this method. B. vulgatus (with smooth LPS) remained sensitive to serum, suggesting that smooth LPS alone is not responsible for serum resistance in Bacteroides.

Although it has been demonstrated that variation in culture conditions can markedly affect sensitivity to serum complement, the biochemical basis is still uncertain. This can be resolved only when the surface chemistry of Bacteroides strains is understood more fully.

This work was funded by the Medical Research Council. We thank C. Blackwood for carrying out preliminary experiments, Dr J. Stewart for helpful suggestions and R. Brown and M. Kerr for practical assistance. 


\section{References}

1. Namavar F, Theunissen EBM, Verweij-Van Vught AMJJ et al. Epidemiology of the Bacteroides fragilis group in the colonic flora in 10 patients with colonic cancer. $J \mathrm{Med}$ Microbiol 1989; 29: 171-176.

2. Gorbach SL, Bartlett JG. Anaerobic infections. $N$ Engl J Med 1974; 290 : 1177-1184, 1237-1245-1289-1294.

3. Duerden BI. The isolation and identification of Bacteroides spp. from the normal human faecal flora. $J$ Med Microbiol $1980 ; 13: 69-78$.

4. Lindberg AA, Berthold P, Nord CE, Weintraub A. Encapsulated strains of Bacteroides fragilis in clinical specimens. Med Microbiol Immunol 1979; 167: 29-36.

5. Onderdonk AB, Kasper DL, Cisneros RL, Bartlett JG. The capsular polysaccharide of Bacteroides fragilis as a virulence factor: comparison of the pathogenic potential of encapsulated and unencapsulated strains. J Infect Dis 1977 ; 136: 82-89.

6. Connolly JC, McLean C, Tabaqchali S. The effect of capsular polysaccharide and lipopolysaccharide of Bacteroides fragilis on polymorph function and serum killing. $J \mathrm{Med}$ Microbiol 1984; 17 : 259-271.

7. Poxton IR, Brown R. Immunochemistry of the surface carbohydrate antigens of Bacteroides fragilis and definition of a common antigen. J Gen Microbiol 1986; 132: 2475-2481.

8. Patrick S, Reid JH. Separation of capsulate and non-capsulate Bacteroides fragilis on a discontinuous density gradient. $J$ Med Microbiol 1983; 16: 239-241.

9. Patrick S, Reid JH, Coffey A. Capsulation of in vitro and in vivo grown Bacteroides species. J Gen Microbiol 1986; 132: 1099-1109.

10. Reid JH, Patrick S, Tabaqchali S. Immunochemical characterization of a polysaccharide antigen of Bacteroides fragilis with an IgM monoclonal antibody. J Gen Microbiol 1987; 133: 171-179.

11. Lutton DA, Patrick S, Crockard AD et al. Flow cytometric analysis of within-strain variation in polysaccharide expression by Bacteroides fragilis by use of murine monoclonal antibodies. J Med Microbiol 1991; 35: 229-237.

12. Taylor PW. Bactericidal and bacteriolytic activity of serum against gram-negative bacteria. Microbiol Rev 1983; 47: 46-83.

13. Crokaert F, Lismont M-J, van der Linden M-P, Yourassowsky E. Determination of complement-mediated serum bactericidal activity against gram-negative bacteria. Rev $\mathrm{Med}$ Microbiol 1992; 3: 241-247.

14. Frank MM, Joiner K, Hammer C. The function of antibody and complement in the lysis of bacteria. Rev Infect Dis 1987; 9 Supplement 5: S537-S545.
15. Leying H, Suerbaum S, Kroll H-P, Stahl D, Opferkuch W. The capsular polysaccharide is a major determinant of serum resistance in K-1-positive blood culture isolates of Escherichia coli. Infect Immun 1990; 58: 222-227.

16. Casciato DA, Rosenblatt JE, Bluestone R, Goldberg LS, Finegold SM. Susceptibility of isolates of Bacteroides to the bactericidal activity of normal human serum. $J$ Infect Dis $1979 ; 140 ; 109-113$.

17. Rotimi VO, Eke PI. The bactericidal action of human serum on Bacteroides species. $J$ Med Microbiol 1984; 18: 355-363.

18. Namavar F, Verweij-Van Vught AMJJ, MacLaren DM. A study of the candidate virulence factors of Bacteroides fragilis. J Gen Microbiol 1991; 137: 1431-1435.

19. Reid JH, Patrick S. Phagocytic and serum killing of capsulate and non-capsulate Bacteroides fragilis. J Med Microbiol $1984 ; 17: 247-257$.

20. Smith H. Pathogenicity and the microbe in vivo. J Gen Microbiol $1990 ; 136: 377-393$.

21. Nelson D, Bathgate AJ, Poxton IR. Monoclonal antibodies as probes for detecting lipopolysaccharide expression on Escherichia coli from different growth conditions. $J$ Gen Microbiol 1991; 137: 2741-2751.

22. Holbrook WP, Duerden BI, Deacon AG. The classification of Bacteroides melaninogenicus and related species. $J$ Appl Bacteriol 1977; 42: 259-273.

23. Van Tassell RL, Wilkins TD. Isolation of auxotrophs of Bacteroides fragilis. Can J Microbiol 1978; 24: 1619-1621.

24. Hudson L, Hay FC. Antibody effector systems. In: Practical immunology, 2nd edn. Oxford, Blackwell Scientific Publications. 1980: 142-145.

25. Fomsgaard A, Shand GH, Freudenberg MA et al. Antibodies from chronically infected cystic fibrosis patients react with lipopolysaccharides extracted by new micromethods from all serotypes of Pseudomonas aeruginosa. APMIS 1993; 101: 101-112.

26. Westphal O, Luderitz O. Chemische erforschung von lipopolysacchariden gramnegativer bakterien. Angew Chem 1954; 66: $407-417$.

27. Laemmli UK. Cleavage of structural proteins during the assembly of the head protein of bacteriophage T4. Nature $1970 ; 227$ : 680-685.

28. Tsai CM, Frasch CE. A sensitive silver stain for detecting lipopolysaccharide in polyacrylamide gels. Anal Biochem 1982; 119: 115-119.

29. Hancock IC, Poxton IR. In: Bacterial cell surface techniques. Chichester, John Wiley and Sons. 1988: 281.

30. Maskell JP. The resolution of bacteroides lipopolysaccharides by polyacrylamide gel electrophoresis. $J$ Med Microbiol 1991; 34: 253-257.

31. Hitchcock PJ, Brown TM. Morphological heterogeneity among Salmonella lipopolysaccharide chemotypes in silver-stained polyacrylamide gels. J Bacteriol 1983; 154: 269-277. 